\title{
Terpsichore reiste mit
}

\author{
S. Weiss
}

«Es wird eine grossartige Gelegenheit sein, das Tanztraining mit Ausflügen an die Adriaküste zu verbinden und jeden Abend an einem Schiffsball teilzunehmen.» Mit diesen Worten kündigte Roland, unser Tanzlehrer, der sich seit einigen Jahren jeden Mittwoch bemüht, uns in die Geheimnisse der Figuren und Schritte von Standard- und südamerikanischen Tänzen einzuführen, die Tanzkreuzfahrt an. Mehrere Schweizer Tanzschulen hatten sich auf dem modernen Kreuzfahrtschiff «European Vision» eingemietet. Auf dem Programm standen tägliche Tanzworkshops sowie abendliche Tanzanlässe.

Schon der Beginn der Reise im Hafen von Venedig war einmalig. Aus einem neuen Blickwinkel in der Höhe eines achtstöckigen Wohnhauses bot sich uns ein Ausblick auf die Serenissima, die bezaubernde Lagunenstadt, und ich konnte bereits die ersten Eindrücke aufs Papier bannen. Die kleine Veranda vor unserer Kabine war ein guter Ort zum ungestörten Malen und Zeichnen und für meine Frau und mich immer

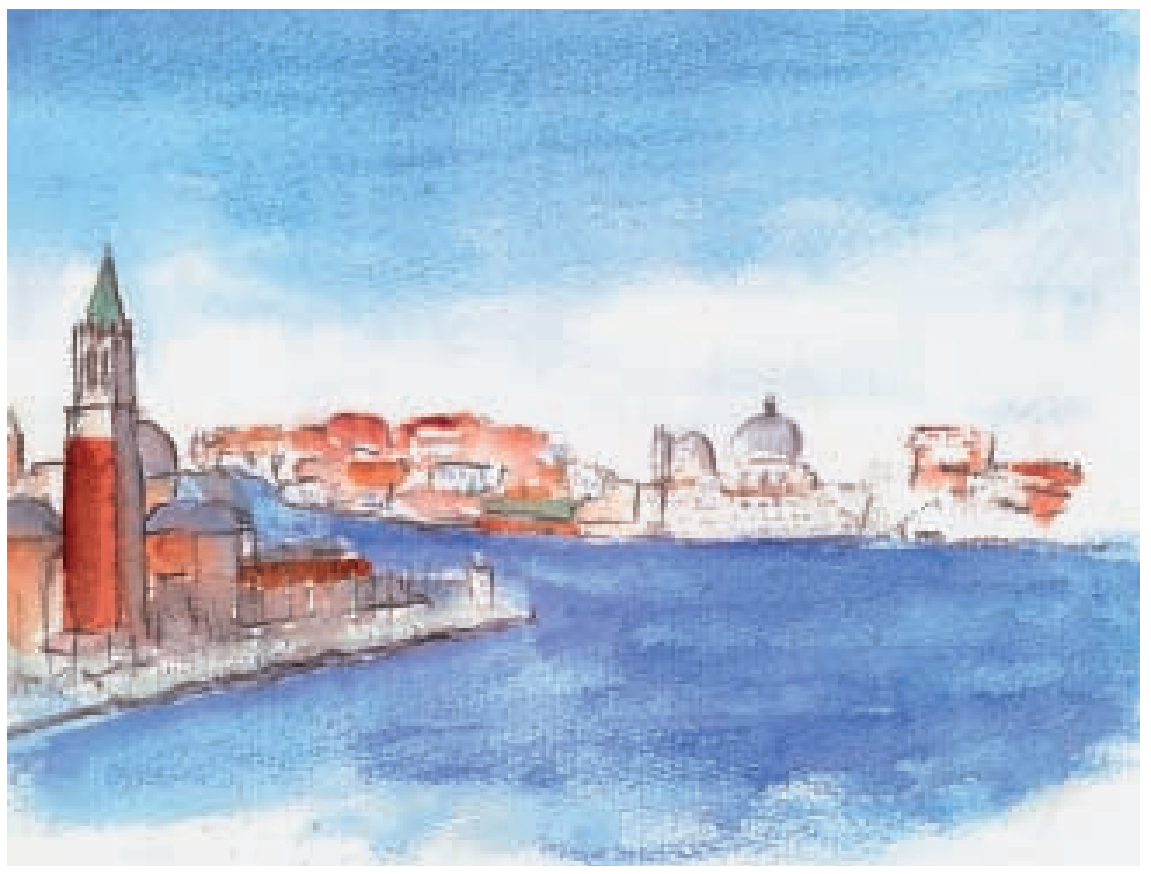

Silhouette Venedigs

Korrespondenz:

Dr. med. Severin Weiss

Effingerstrasse 14b

CH-3011 Bern ein erholsamer Ort der Ruhe, wenn es auf Deck des Riesenschiffes, auf dem 1600 Personen mitreisten, allzu lärmig und ausgelassen wurde. Die geruhsame und sehr gemütliche Fahrt durch den Canale della Giudecca entlang der Gebäude der Piazza San Marco gestaltete sich sehr eindrücklich durch immer neue Einblicke aus luftiger Höhe in das belebte Venedig.

Durch die offene Adria führte uns unsere schwimmende Stadt nach Absolvierung der üblichen SOS-Übung hinüber an die dalmatinische Küste Richtung Dubrovnik. Mit einem Landausflug bot sich die Gelegenheit, die schöne alte Stadt mit ihren Festungen und eindrücklichen Türmen zu bewundern. Zum Nachtessen wurden wir jeweils durch sehr aufmerksame Kellner mit einem mehrgängigen, hervorragenden 5-GangMenu und guten Weinen verwöhnt.

Nach tiefem, erholsamem Schlaf bei offener Balkontür begann am nächsten Morgen unser erster Tanzunterricht im Raum Flamenco-Disco im 12. Stock. Und hier, beim Anblick der riesigen Heckwelle unseres majestätischen Schiffes, tanzend und schwebend zur Musik, spürten wir erstmals die Anwesenheit der Muse des Tanzes, Terpsichore, Tochter des Zeus und der Mnemosyne, die das Schiff begleitete. Dank der Stabilisatoren war die ganze Fahrt über Korfu, um den Peloponnes herum, zur farbenprächtigen Insel Santorin, bis hinunter nach Rhodos und dann zurück nach Athen, trotz Gewittern sehr ruhig.

Mit der Bordzeitung wurden wir jeden Tag über die vielseitigen Aktivitäten auf dem Schiff und auch über die Landausflüge informiert. So erfuhren wir, dass am zweiten Abend ein grosser Ball stattfand, wo wir zu den Klängen des Bordorchesters die am Morgen geübten Tanzschritte anwenden konnten. Besonders bei der Tanzdemonstration durch unsere Tanzlehrer an einem der nächsten Abende schwebte der Geist Terpsichorens wieder im Raum und freute sich mit uns an den meisterhaften und gekonnten Tanzdarbietungen. Unser Tanzlehrer Roland eroberte vor drei Jahren den Weltmeistertitel im DiscoFox und zeigte uns auf dem Schiff eine unglaubliche Salsa-Kür, die uns in ihren Bann zog und mitriss. Auch die Shows der andern Tanzlehrer waren von höchster Qualität und bereiteten uns viel Genuss und reine Freude. Einmal mehr wurde uns bewusst, wieviel Kunst im Tanzen liegen kann! 


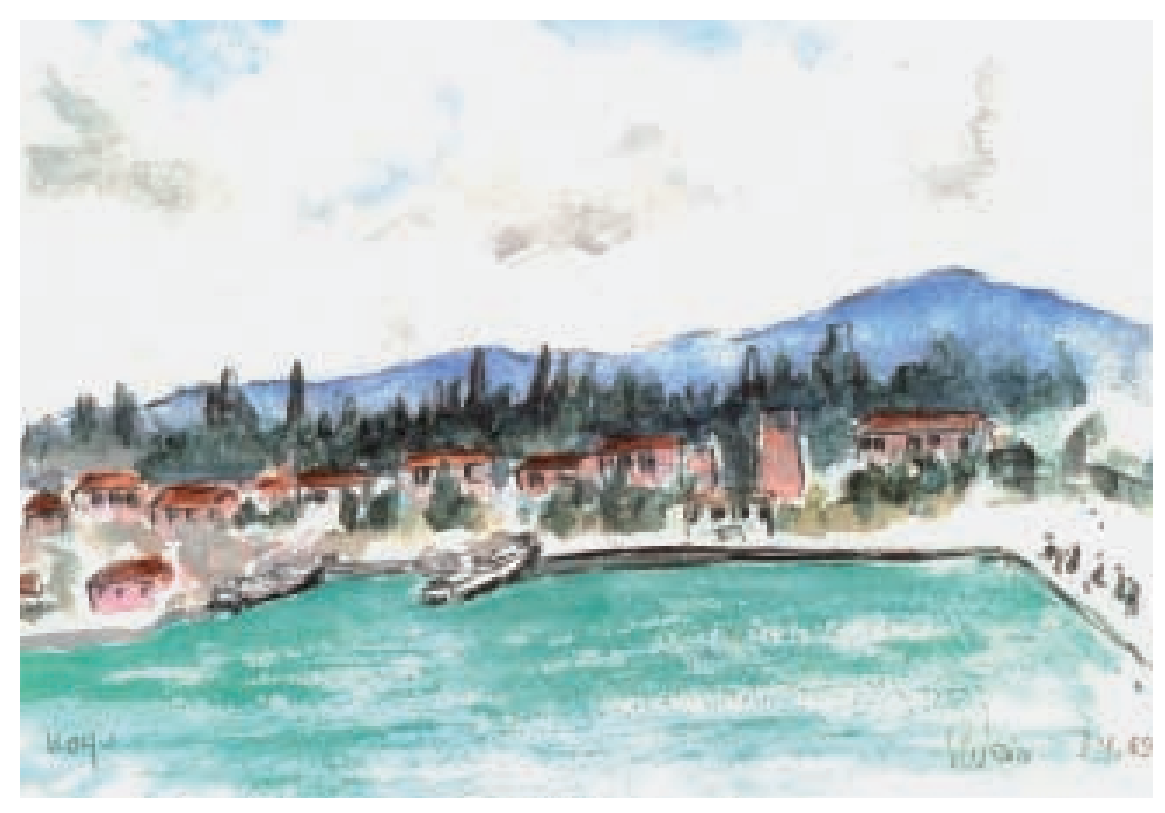

Hafen Korfu

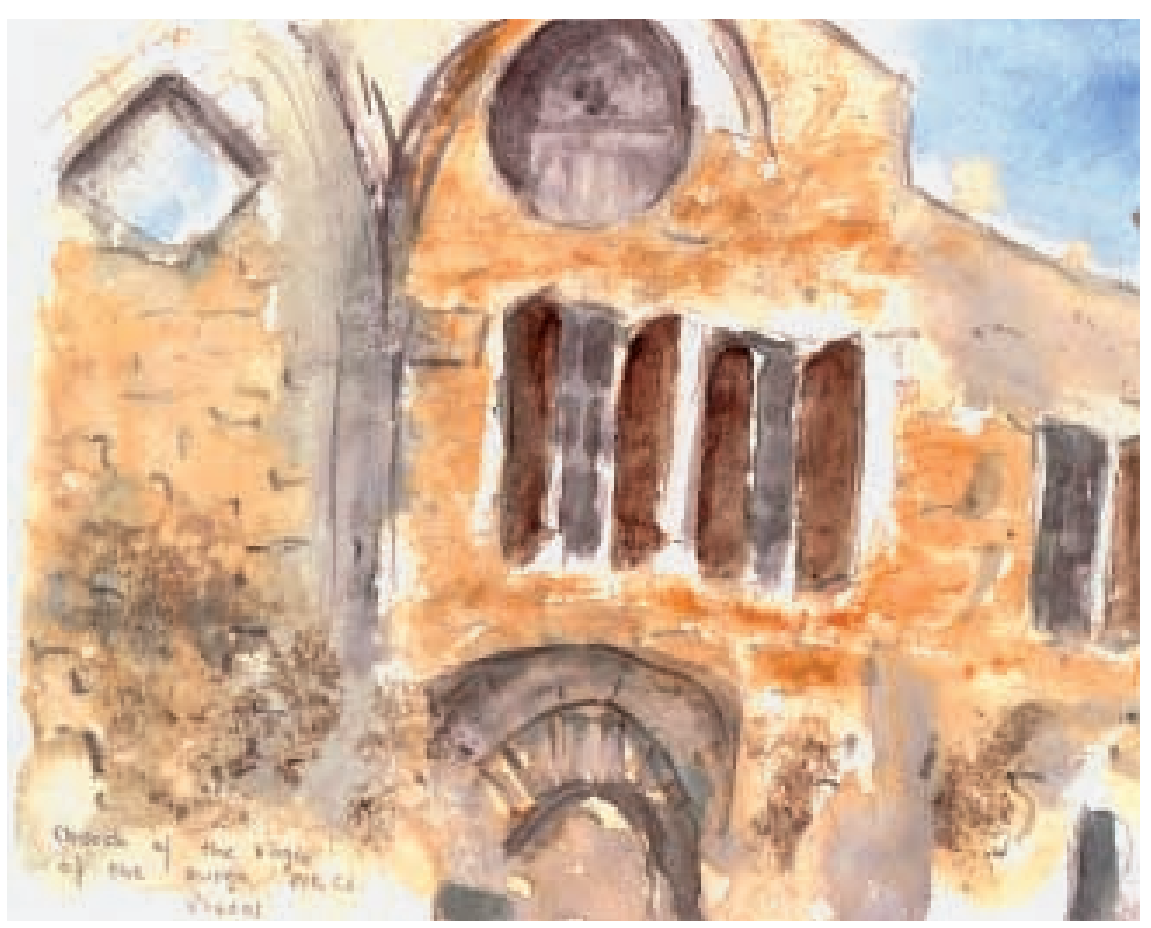

Church of the Virgin of the Burgh, Rhodos
Schon aus weiter Ferne erschien im Ionischen Meer die langgestreckte Silhouette einer Insel. Zunächst glaubte man schneebedeckte Zinnen auf schwarzbrauner Erde zu erblicken, bis man etwa näherkommend feststellte, dass es die weissen Häuser auf der Kuppe der Insel waren, die diesen Eindruck hervorriefen. Mit Tenderbooten wurden wir an Land gebracht. Beim jähen Anstieg in den Touristenort Firà konnten wir langsam erahnen, was für eine unglaubliche Katastrophe sich vor über dreitausend Jahren auf dieser Vulkaninsel abspielte. Ein grosser Teil der Insel wurde damals in die Luft geschleudert, versank dann in 400 Metern Tiefe und führte wahrscheinlich zum Untergang der kretischminoischen Kultur. Heute ist eine riesige Caldera, Überreste eines Kraters, zurückgeblieben und auf dem verbleibenden Inselrest werden heute Ausgrabungen bis in einer Tiefe von über zwanzig Metern durchgeführt, wo unter der Lava ähnliche Funde wie in Pompeji gemacht werden.

Die nächste Insel der Ägäis, Rhodos, bezauberte uns durch die mittelalterlichen Stadtmauern, durch das intensive Leben im Hafen mit dem Ausladen der Fähren und dem griechischen Temperament der Ortsansässigen.

Unser letzter Anlegeort, der Hafen Piräus, und besonders der Ausflug auf die immer wieder tief berührenden Ruinen der Akropolis mit dem Parthenon, dem Erechtheion mit den Karyatiden, begeisterte uns durch eine durch den Regen am Vortag einmalig klare Sicht. So konnten wir ein eindrückliches Panorama der Riesenstadt Athen bewundern, sahen nicht nur den Nachbarhügel Lykabettos, sondern unser Blick konnte frei bei nach Piräus und hinüber bis ins eleusische Hügelland schweifen.

Eine lange Nachtreise führte uns zurück an den Ausgangspunkt, und Venedig empfing uns mit einem tiefblauen Himmel, so dass wir die Silhouette der Stadt nochmals bei strahlendem Sonnenschein vor uns hatten. 